\title{
T2*-Weighted MR Images of a Patient with Familial Cerebral Cavernous Malformation
}

\author{
Kengo Maeda, Tomoya Terashima, Hiromichi Kawai and Mitsuru Sanada
}

Key words: familial cavernous malformation, MRI, T2-weighted, microbleeding

\section{(DOI: 10.2169/internalmedicine.46.6461)}

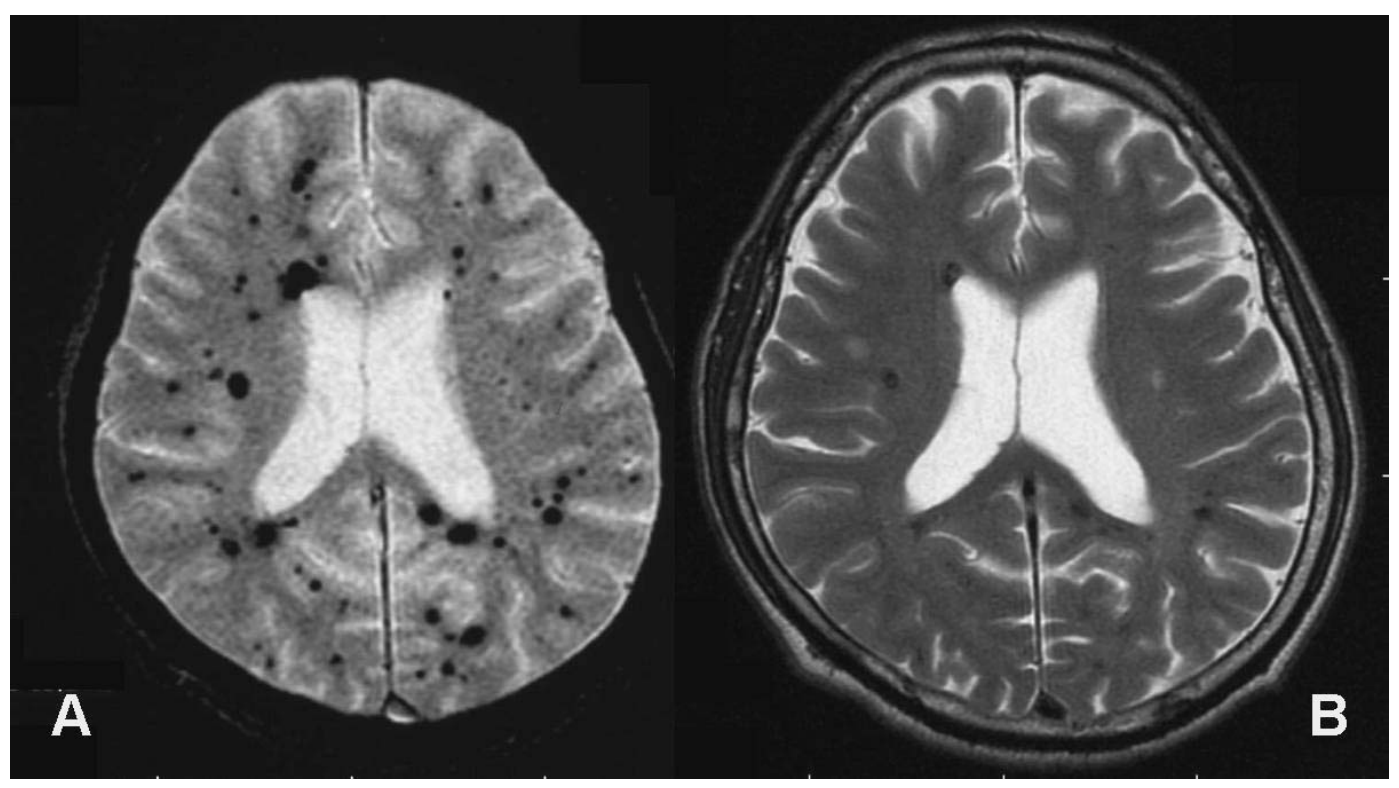

A 58-year-old man presented with left foot numbness. Subsequent neurological evaluation revealed multiple cavernous malformations within the cerebrum, cerebellum, brainstem, and thoracic spinal cord. His son had suffered from cerebellar hemorrhage at the age of 15 , when he was diagnosed as having cavernous malformation. Our patient was diagnosed as having familial cerebral cavernous malformation showing autosomal dominant inheritance. Large lesions were treated with a gamma knife.
T2*-weighted magnetic resonance imaging (Picture A) revealed numerous hypointense lesions indicating microhemorrhages from cavernous malformations compared with conventional T2-weighted imaging (Picture B). The usefulness of $\mathrm{T}^{*}$-weighted magnetic resonance imaging for detection of familial cerebral cavernous malformations has been reported previously $(1,2)$. T2 ${ }^{*}$-weighted imaging was superior to the conventional T2-weighted imaging in the detection of lesion number and distribution.

\section{References}

1. Brunereau L, Leveque $C$, Bertrand $P$, et al. Familial form of cerebral cavernous malformations: evaluation of gradient-spin-echo
(GRASE) imaging in lesion detection and characterization at 1.5 T. Neuroradiology 43: 973-979, 2001.

Division of Neurology Department of Medicine, Shiga University of Medical Science, Otsu Received for publication December 25, 2006; Accepted for publication January 30, 2007

Correspondence to Dr. Kengo Maeda, kengo@belle.shiga-med.ac.jp 
DOI: 10.2169/internalmedicine.46.6461

2. Lehnhardt F-G, von Smekal U, Rückriem B, et al. Value of gradient-echo magnetic resonance imaging in the diagnosis of fa- milial cerebral cavernous malformation. Arch Neurol 62: 653-658, 2005.

(C) 2007 The Japanese Society of Internal Medicine http://www.naika.or.jp/imindex.html 